\title{
Genre Analysis of Research Article Abstracts in Linguistics and Literature: A Cross Disciplinary Study
}

\author{
Ijaz Asghar Bhatti ${ }^{1}$, Sahar Mustafa ${ }^{1} \&$ Musarrat Azher $^{1}$ \\ ${ }^{1}$ Department of English, University of Sargodha, Pakistan \\ Correspondance: Dr. Musarrat Azher, Department of English, University of Sargodha, Pakistan. Email: \\ musarratazher@gmail.com
}

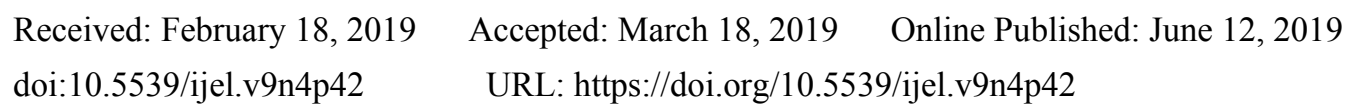

\begin{abstract}
The importance of an abstract in a research article has turned the focus of linguistics on Genre analysis of abstract articles. Taking into consideration this immensely researched topic, this paper aims to investigate the macro and micro structures in the Linguistics and Literature Abstracts. In the previous researches, this very comparison is never addressed by the researches, hence the present research aims to fill this gap. The corpus contained 40 abstracts, 20 of linguistics and 20 of literature from International Journal of Applied Linguistics \& English Literature (IJALEL). The macro analysis was made according to the Create a Research Space (CARS) model by Swales (2004) and Ant mover software was used to analyze the corpus, while the micro analysis followed Swales and Feak (2009). The results showed that there is no significant difference between the linguistics and literature abstracts at the macro level while the differences lie at the micro level. This study will be beneficial for the novice researchers as it provides a framework of analyzing two interconnected disciplines.
\end{abstract}

Keywords: genre analysis, research article abstracts, linguistics, literature

\section{Introduction}

English language is the language of the world today and is used as lingua franca in all the fields including research and technology. The knowledge of English allows professionals and researchers "to get access to the latest information in their fields and to effectively communicate with their colleagues throughout the world". (Yakhontova, 2003, p. 14). Various researches in the English language are published in the journals around the world and research articles (RA) have now become the centre of importance in academia. Through RAs, "people in the scientific community can keep up with the latest developments in their own fields and may build on the present research and make their own contributions to their fields" (Zhang \& Zhang, 2014, p. 31).

Further, in the research and academic writing, genre analysis holds significant importance. The genre was first introduced in the area of ESP in the 1980s (Marefat \& Mohammadzadeh, 2013, p. 39). Here comes a question that what is genre? Swales (1990) was the one who gave an extensive definition of the genre after studying it in various aspects, according to him:

"A genre comprises a class of communicative events, the members of which share some set of communicative purposes. These purposes are recognized by the expert members of the parent discourse community, and thereby constitute the rationale for the genre. This rationale shapes the schematic structure of the discourse and influences and constrains choice of content and style" (p. 58).

The genre is also very significant in discourse analysis and is one of the levels contributing to discourse analysis. At various times and in various areas of study, genre has been defined and used mainly as a classificatory tool, a way of sorting and organizing kinds of texts and other cultural objects (Othman, 2011, pp. 67-68). Flowerdew (2014) defines genre analysis as Genre Analysis is the study of situated linguistic behaviour in institutionalised academic or professional settings (p. 22).

A lot of work has been done on the genre analysis of research articles. Swales (1981, 1990, 2002, 2004), Hyland (2000, 2005, 2009, 2013) Dudley Evans's (1986, 1988), Bhatia (1993), Lores (2004), Santo (1996), Cross (2006) and many more researchers wrote on the genre analysis of research articles. There are certain moves which aid in the genre analysis and this process of applying moves on a text is called moves analysis. Move analysis is a helpful tool in genre studies since moves are semantic and functional units of texts, which can be identified 
because of their communicative purposes and linguistic boundaries. (Ding, 2007, p. 270). Santos (1996) defines a move as a move has to be considered as a genre stage which has a particular, minor communicative purpose to fulfill, which in turn serves the major communicative purpose of the genre (Dos Santos, 1996, p. 485). The most prominent move structures are Create A Research Space (CARS) and Introduction, Method, Results and Discussion (IMRaD) by Swales (1990), 4 moves structure by Bhatia (1993), 5 moves structure by Santos (1996), Introduction, Purpose, Method, Product and Conclusion (IPMPC) by Hyland (2000).

Genre analysis of research article abstracts has taken a very important position in the field of research. Though not as widely researched as research articles, abstracts have drawn the attention of a number of genre researchers over the past two decades (Lorés Sanz \& Bondi, 2014, p. 9). Abstracts are not actually the part of a research article but stand independently and are integral for the creation of a quality research work. In cases where readers are uncertain from the title whether the paper contains material of interest to them, the abstract assists them by informing them more precisely of what the article covers (Dos Santos, 1996, p. 482). Koltay (2010) defines an abstract as:

"An abstract is a text that reflects the most important information of an existing (primary) text in a form shorter than the original. The importance of information is decided from a pre-defined viewpoint, which enables the abstract to serve informing (informational) goals" (p. 26).

According to Koltay (2010), there are three main types of abstracts as the indicative or descriptive abstract, the informative abstract, the indicative-informative (mixed) abstract. Indicative or Descriptive abstracts provide the description of the complete article in a brief way while informative abstracts provide the required information in the form of narration. The indicative-informative abstracts provide the mixed approach.

Many researchers worked on this very topic of research article abstracts and most of them made a comparison between the native and non-native abstracts. Some focused on the abstracts of sciences, some on the social sciences and some compared the abstracts of sciences and social sciences. A less or none importance is given to the comparison of linguistics and literature abstracts, hence to fill this gap the present research will illustrate the contrastive analysis of the linguistics and literature abstracts.

\subsection{The Aim of the Research}

This research paper aims to investigate the differences and similarities between the English linguistics and literature abstracts and to highlight how far the difference in the discipline affects the structure of abstracts. By keeping this in view, three research questions are to be addressed in this paper:

1) How are the move structures of the abstracts different or similar in linguistics and literature abstracts?

2) Which moves are common in the abstracts of these two disciplines?

3) What differences at the macro or micro level, help to distinguish the abstracts of these two disciplines?

\section{Literature Review}

Genre analysis of research articles is a widely addressed topic in research, Zhang and Zhang (2014) found that 85 of the 448 research articles in the 97 issues of the journals published from 1986 to 2012 were concerned with research articles. A number of researches have been published on the genre analysis of research articles' introduction sections, acknowledgements and abstracts. The genre analysis of RA abstracts is very integral and useful practice as it provides the researches with the recent trends in abstract writing. A finely written abstract is the key to publish an article hence abstract writing must be given keen importance. By keeping in view this vast significance of RA abstracts particularly in research and generally in ESP, many linguistics are taking interest in this very topic from the last three decades.

Swales (1981) was the one who introduced the macro structures of RA abstract analysis. He gave a move structure model for RA introductions which was later named as Create a Research Space (CARS) model. Further, he gave a move structure model in 1996 which contained the following 5 moves: Situating the research, Presenting the research, Describing methodology, Summarizing the findings and Discussing the findings. Later on, Swales (1990), Bhatia (1993) and Lores (2004) presented a rhetorical structure named as IMRD model which contained the following 4 moves: Introduction, Methodology, Result and Discussion. In the case of micro structures of RA abstracts, Hyland (2005) is the one who gave a description of micro structures regarding RA abstracts in his book "Metadiscourse".

Various researches have been made on this very topic of genre analysis of RA abstracts and mostly the researchers shed light on the native and non-native abstracts comparison. Behnam and Golpour (2014) gave a comparison between English and Iranian RA abstracts in the two disciplines of mathematics and applied 
linguistics. They pointed out the cross-linguistic and cross-disciplinary variations by using the move structure method of Hyland (2000). They highlighted the importance of move step analysis and explained that, the knowledge obtained from the cross - linguistic analysis has displayed how move step analysis is a valuable analytical tool for understanding cultural differences in the rhetorical structure of RA abstracts (Behnam \& Golpour, 2014, p. 178).

Al-Khasawneh (2017) also addressed the differences between the native and non-native RA abstracts. He also applied the Hyland (2000) model and gave the result that both the writers gave importance to the moves but the striking difference was found in the Introduction and Conclusion moves. Native writers tend to include these two moves much more frequently compared to non-native writers (Al-Khasawneh, 2017, p. 11).

Noorizadeh-Honami and Chalak (2018) also pointed out the cross-linguistic and cross-cultural differences between the RA abstracts. They applied the IMRD Swales (1990) on their research and compared the Persian and English abstracts. According to them, the Persian authors preferred to provide more information in their Introduction and Discussion moves compared to English authors. On the other hand, English authors presented more information in their Method move (Noorizadeh-Honami \& Chalak, 2018, p. 329).

Marefat and Mohammadzadeh (2013) compared the Persian and English RA abstracts by applying IMRD and CARS model by Swales. They pointed out that the norms of a community are the contributing factor in the writing styles of the researchers.

Belyakova (2017) gave a cross-linguistic study of English and Russian RA abstracts by applying Biber (1998) model and analyzed that the Russian authors seem to skip the Results move much more often than their native English colleagues (Belyakova, 2017, p. 40).

Ghasempour and Farnia (2017) also compared the English and Persian abstracts according to Hyland (2000) and gave the conclusion that the purpose, method, and conclusion moves were used more than introduction and result moves in English abstracts while introduction, purpose and conclusion moves more than method and result moves in Persian abstracts (Ghasempour \& Farnia, 2017, p. 749).

Farzannia and Farnia (2017) compared the English and Persian RA abstracts in mining engineering journals by applying Hyland (2000) model and pointed out that except purpose move no significant difference was found between two groups under investigation (Farzannia \& Farnia, 2017, p. 10).

$\mathrm{Li}$ (1911) in his thesis presented the cross-linguistic and cross-disciplinary analysis of RA abstracts by following Hyland (2000) model and illustrated the result that the English abstracts are more likely to contain the canonical moves while there are more moves deletions in Chinese abstracts (Li, 1911, p. 39).

Another work by Majid and Omid (2017) showed the comparison between Iranian and English RA abstracts in which they analyzed the rhetorical moves applied in research papers. According to their research, no significant differences between two corpora were found and they hypothesized that the Hyland's (2000) model is suitable for analyzing the abstracts in the field of agricultural engineering (Majid \& Omid, 2017, p. 120).

Apart from the comparison between native and non-native RA abstracts, some researchers also focused on the cross-disciplinary analysis. The work by Suntara and Usaha (2013) showed the comparison between linguistics and applied linguistics projects. They applied Hyland (2000) move analysis model in their research and pointed out that the most frequent patterns in the field of linguistics were P-M-Pr-C, P-M-Pr, and I-P-M-Pr. In the field of applied linguistics, the writers' preference patterns were P-M-Pr-C, I-P-M-Pr-C, and I-P-M-Pr (Suntara \& Usaha, 2013, p. 97).

Darabad (2016) presented the cross-disciplinary RA abstracts research between Applied Linguistics, Applied Mathematics, and Applied Chemistry by following the Hyland (2000) model. According to him most of the abstracts in Applied Linguistics and Applied Mathematics disciplines were composed of 4 moves. In Applied Chemistry corpus, however, the majority of abstracts included only three moves (Darabad, 2016, p. 135).

Saboori and Hashemi (2013) gave the cross-disciplinary analysis of RA abstracts between the applied linguistics, applied economics, and mechanical engineering. By applying Hyland (2000) model they concluded that the abstracts from all three disciplines contained the purpose and product which means that these two are the obligatory moves in these disciplines. Apart from the similarity the major difference concluded by them was that the AL abstracts had a variety of moves without any repetition while the ME abstracts were opposite to them. The abstracts of AE somehow were similar to the patterns of ME.

El-Dakhs (2018) gave a comparison between RA abstracts of more and less prestigious journals. By using Hyland (2000) move structure model with Hyland (2005) taxonomy of metadiscourses she analyzed that the 
abstracts of less prestigious journals contained longer move structures for introduction, purpose and method while the more prestigious journal abstracts contained longer structure for the findings move. In the metadiscourse analysis, she found that the less prestigious journal abstracts had a purpose and addition connectives in method and findings while more prestigious journal abstracts had contrast connectives in the findings.

A glimpse at all these works discloses that there are a lot of works on cross-disciplinary analysis of RA abstracts but no work has been found in which the linguistics and literature abstracts are compared. To shed light on this unique comparison the present study aims at finding macro and micro structures of the abstracts.

\section{Research Methodology}

This investigative study aims at comparing the micro and macro structure of Research article abstracts in English language and literature abstracts by using CARS model by Swales (2004) for macro structures analysis and Swales and Feak's (2009) model for micro structure analysis. The CARS model is a very diverse model for analyzing research article abstract and it contains the sub-moves which comprehensively explains the move structure. Moreover, this model is followed by the Ant Mover software as well, which made it convenient to analyze the corpus. For the micro level Swales and Feak's (2009) model was selected because it gave the framework for deeply analyzing a text.

The CARS model (2004) contains the following moves:

Table 1. CARS by Swales (2004) adopted by Marafat, Mohammadzadeh, (2013)

\begin{tabular}{l} 
I1 Establishing Research Territory \\
I1s1 Claiming centrality \\
I1s2 Making topic generalisations \\
I1s3 Reviewing items of previous research \\
\hline I2 Establishing a niche \\
I2s1A Indicating a gap \\
I2s1B Adding to what is known \\
I2s2 Presenting positive justification \\
\hline I3 Presenting Present Research \\
I3s1 Announcing present research purposively/descriptively \\
I3s2 Presenting research questions/hypotheses \\
I3s3 Definitional clarification \\
I3s4 Summarising methods \\
I3s5 Announcing principle outcomes \\
I3s6 Stating the value of present paper \\
I3s7 Outlining structure of paper
\end{tabular}

The micro analysis by Swales and Feak's (2009) used in this research consists the following variables:

- Length of abstract

- Use of tense

- Presence of any citation

- Presence of 1st person pronoun

- Meta discourse references

- Acronyms

\subsection{Data Collection}

The corpus for this study was selected from International Journal of Applied Linguistics \& English Literature (IJALEL) Volume7 No. 5; 2018, Volume 7 No. 3; 2018, Volume 7 No. 4; 2018. The corpus consisted of 40 abstracts, selected randomly. The recent abstracts selection was taken into consideration as the modern trends in the abstracts of two disciplines were to be compared.

\subsection{Data Analysis}

Following steps have been followed during the data analysis procedure: 
Table 2. Data analysis steps

\begin{tabular}{ll}
\hline Level 1 & Level 2 \\
\hline Macro structure analysis is done on the basis of CARS model by & Micro structure analysis followed Swales and Feak's (2009) model. \\
Swales (2004) & \\
\hline
\end{tabular}

For macro analysis the Ant Mover software was used which is a text structure analysis program developed by Anthony Laurence (2003). Whereas, for the micro analysis the abstracts were keenly read and the variables were found in reach of the abstract in the corpus.

\section{Results and Discussion}

\subsection{Results at Macro Level}

The following table shows the results on disciplinary variation at macro level.

Table 3. Distribution of moves, numbers and percentages in abstracts

\begin{tabular}{lll}
\hline MOVES & LINGUISTICS ABSTRACTS & LITERATURE ABSTRACTS \\
\hline I1s1 Claiming centrality & $3(15 \%)$ & $1(5 \%)$ \\
I1s2 Making topic generalisations & $16(80 \%)$ & $17(85 \%)$ \\
I1s3 Reviewing items of previous research & $\mathrm{Nil}$ & $\mathrm{Nil}$ \\
I2s1A Indicating a gap & $\mathrm{Nil}$ & $\mathrm{Nil}$ \\
I2s1B Adding to what is known & $\mathrm{Nil}$ & $\mathrm{Nil}$ \\
I2s2 Presenting positive justification & $\mathrm{Nil}$ & $\mathrm{Nil}$ \\
I3s1 Announcing present research purposively/descriptively & $14(70 \%)$ & $13(65 \%)$ \\
I3s2 Presenting research questions/hypotheses & $\mathrm{Nil}$ & $\mathrm{Nil}$ \\
I3s3 Definitional clarification & $\mathrm{Nil}$ & $\mathrm{Nil}$ \\
I3s4 Summarising methods & $\mathrm{Nil}$ & $\mathrm{Nil}$ \\
I3s5 Announcing principle outcomes & $20(100 \%)$ & $20(100 \%)$ \\
I3s6 Stating the value of present paper & $16(80 \%)$ & $11(55 \%)$ \\
I3s7 Outlining structure of paper & $\mathrm{Nil}$ & $\mathrm{Nil}$ \\
\hline
\end{tabular}

The analysis of the 20 Linguistics abstracts revealed that 9 out of the 20 abstracts started from the I3s 1 Announcing present research purposively/descriptively move and 8 abstracts started from the I1s2 Making topic generalisations move while 3 of the abstracts started from I1s1 Claiming centrality move. Moreover, $15 \%$ of the linguistics abstracts contained I1s1 Claiming centrality move, $80 \%$ had I1s2 Making topic generalisations move, $70 \%$ had I3s1 Announcing present research purposively/descriptively move, $80 \%$ had I3s6 Stating the value of present paper move and all the abstracts had I3s5 Announcing principle outcomes move. Move 2 Establishing a niche, was not present in any of the linguistics abstracts.

On the other hand, in literature abstracts 10 abstracts out of 20 started from the I1s2 Making topic generalisations move, 7 of the abstracts started from I3s1 Announcing present research purposively/descriptively move while rest of the 3 abstracts started from I3s6 Stating the value of present paper move, I3s5 Announcing principle outcomes move and I1s1 Claiming centrality move respectively. Moreover, 5\% of the literature abstracts contained I1s1 Claiming centrality move, $85 \%$ had I1s2 Making topic generalisations move, $65 \%$ had I3s1 Announcing present research purposively/descriptively move, 55\% had I3s6 Stating the value of present paper move and all the abstracts had I3s5 Announcing principle outcomes move. Move 2 Establishing a niche, was not present in any of the literature abstracts.

\subsection{Results at Micro Level}

The following table shows the macro level results: 
Table 4. Variables in the abstracts

\begin{tabular}{lll}
\hline VARIABLES & LINGUISTICS ABSTRACTS & LITERATURE ABSTRACTS \\
\hline length of abstract & $14(70 \%)$ less than 250 words & $7(35 \%)$ less than 250 words \\
& $3(15 \%)$ less than 200 words & $8(40 \%)$ less than 200 words \\
& $1(5 \%)$ less than 150 words & $4(20 \%)$ less than 150 words \\
& $1(5 \%)$ above 300 words & $1(5 \%)$ above 250 words \\
& $1(5 \%)$ less than 100 words & \\
Use of tense & $17(85 \%)$ present tense & $12(60 \%)$ present tense \\
& $17(85 \%)$ Passive construction & $17(85 \%)$ Passive construction \\
Presence of any citation & $6(30 \%)$ & $19(95 \%)$ \\
Presence of 1st person pronoun & Nil & Nil \\
Metadiscourse references & $16(80 \%)$ & $13(65 \%)$ \\
Acronyms & $13(65 \%)$ & $2(10 \%)$ \\
\hline
\end{tabular}

At the micro level the abstracts were analyzed to identify the variables i.e., length of abstract, use of tense, presence of any citation, presence of 1st person pronoun, meta discourse references, cross cultural references.

The length of the linguistics and literature abstracts were almost similar. $70 \%$ of the linguistics abstracts contained less than 250 words while majority (40\%) of the literature abstracts contained less than 200 words. This variation in the length of abstract in the two disciplines shows that the linguistics abstracts needs more explanation than the literature abstract. This is may be due the fact that the linguistics abstracts include more technicalities than the literature abstracts. On the other hand, literature abstracts are only providing the information in a brief manner. An exception was noted that two of the linguistics abstracts were showing maximum and minimum word count i.e., less than 100 words and more than 300 words respectively. This exception shows that linguistics abstracts can also be brief at times. This type of exception was not found in the literature abstracts.

In majority of the Linguistics and Literature abstracts, present tense was used. $85 \%$ of the linguistics while $60 \%$ of the literature abstracts were in present tense. The use of passive voice was found to be similar in the abstracts of both disciplines i.e., 17 out of 20 linguistics and literature abstracts had passive constructions.

$95 \%$ of the literature abstracts contained citation while only $30 \%$ of the linguistics abstracts had citations. It is due to the fact that in literature abstracts, the writings of the authors are addressed which are to be analyzed.

None of the abstracts contained 1st person pronoun.

The Metadiscourse features as: Logical connections, frame makers, evidential, Hedges and boosters i.e. (this study, the article, in addition, but, here etc.) were present in abstracts of both disciplines. $80 \%$ of the linguistics and $65 \%$ of the literature abstracts abstracts had metadiscouse references.

The abbreviations or acronyms were widely used in the linguistics abstracts as it contained the names of some research tools i.e., (SPSS, FLSAS, MANOVA etc.), names of tests i.e., (IELTS), names of languages (EFL, L1, L2 etc.). $65 \%$ of the linguistics abstracts contained acronyms while on the other hand only $10 \%$ of the literature abstracts contained acronyms.

\subsection{Comparison of Result with Previous Studies}

Suntara and Usaha (2013) presented the variations between the Linguistics and Applied Linguistics research article abstracts by applying Hyland (2000) move structure model. They found that the Purpose, Method and the Product moves were conventional moves in abstracts of both fields. Whereas the conclusion move was optional in the field of linguistics but was conventional in applied linguistics field. It was observed that this difference in the moves was due to the discipline specificity, applied linguistics is a practical subject which includes practical issues as pedagogical applications, due to this fact the conclusion section in the research article abstracts is mandatory. The analysis of Suntara and Usaha (2013) was based on the macro level only and the difference between the move structures were presented between the two disciplines. In the present study the comparison is not only based on macro level but micro analysis is also performed to understand the minute differences between the linguistics and literature abstracts.

Darabad (2016) presented the variations between the Applied Linguistics, Applied Mathematics, and Applied Chemistry research article abstracts by applying Hyland (2000) move structure model. He analyzed that in all the three disciplines introduction move was the least frequent move and Purpose, Method, Result and Conclusion (PMRC) was the most frequent move pattern. The study of Darabad (2016) counters the belief of Hyland (2000) that Applied Chemistry is a hard discipline. He observed that the abstracts of Applied Chemistry had repetition 
in the move structures while the abstracts of Applied Linguistics had a very limited variety of moves with no repetition while the position of Applied Mathematics abstracts was between the other two disciplines. Apart from this, mixing process of moves were also found in all three disciplines. It was identified that mixed Purpose-Method move was present in some Applied Linguistic and Applied Chemistry abstracts. Another mixing process was found in the Applied Mathematics and Applied Chemistry corpus where a combination of purpose and product moves were identified. The frequency of moves and tenses used in the abstracts were also analyzed by him. Whereas in the present study the frequency of moves is not identified, only the occurrence of moves in the Linguistics and literature abstracts is found. The study of Darabad (2016) is not dealing with the micro analysis of abstracts, he has only given the information regarding tense used in the abstracts, while in the present study Length of abstract, use of tense, Presence of any citation, Presence of 1st person pronoun, Meta discourse references and Acronyms were also identified.

\section{Conclusion}

The comparison between the linguistics and literature abstracts showed the following results:

Macro level: At macro level we can conclude that both the linguistics and literature abstracts had two moves: Move 1 (Establishing Research Territory) and Move 3 (Presenting Present Research), while Move 2 (Establishing a niche) was missing in the abstracts of both disciplines. The frequency of moves and move patterns were also similar in the two disciplines, the most frequent move was I3s5 Announcing principle outcomes.

Micro level: At micro level certain differences are noted between the abstracts of two disciplines. The most prominent difference was the abundant presence of citations in the literature abstracts i.e., $95 \%$, contrary to this, only $30 \%$ of the linguistics abstracts contained citations. Another contract was the plentiful use of acronyms in linguistics abstracts i.e., $65 \%$ while only $10 \%$ of the literature abstracts contained acronyms.

We can conclude that apart from being different disciplines, the comparison between linguistics and literature abstracts did not show any significant difference at the macro level. While at the micro level we found prominent difference among the RA abstracts of two disciplines. Hence, we can conclude that the linguistics and literature abstracts are similar at macro level but show prominent differences at the micro level. The present study reveals that to analyze the RA abstracts of two interrelated or closely related disciples, one must carry the micro level analysis along with the macro analysis.

All three research questions are answered in the results as we can see that the move structures of linguistics and literature abstracts are quite similar to each other. The common moves in the abstracts of two disciplines are Move 1 (Establishing Research Territory) and Move 3 (Presenting Present Research). Further, we cannot distinguish the abstracts of linguistics and literature at the macro level, but at the micro level the abundant presence of citations in the literature abstracts i.e., $95 \%$, and less citations i.e. $30 \%$ in the linguistics abstracts marks difference. Another contract is the plentiful use of acronyms in linguistics abstracts i.e., $65 \%$ while the literature abstracts contained only $10 \%$ of acronyms.

The research is significant in the field of genre analysis and highlights the similarities and differences between abstracts of linguistics and literature both at macro and micro levels. The results may be used for further research purposes and comparative studies may be carried out by focusing on other disciplines.

\section{References}

Al-Khasawneh, F. M. (2017). A genre analysis of research article abstracts written by native and non-native speakers of English. Journal of Applied Linguistics and Language Research, 4(1), 1-13.

Anthony, L. (2003). AntMover (Version 1.1.0) [Computer Software]. Tokyo, Japan: Waseda University. Retrieved from http://www.laurenceanthony.net/software

Behnam, B., \& Golpour, F. (2014). A genre analysis of English and Iranian research articles abstracts in applied linguistics and mathematics. International Journal of Applied Linguistics and English Literature, 3(5), 173179. https://doi.org/10.7575/aiac.ijalel.v.3n.5p.173

Belyakova, M. (2017). English-Russian cross-linguistic comparison of research article abstracts in geoscience. https://doi.org/10.14198/ELUA2017.31.02

Darabad. A. M. (2016). Move Analysis of Research Article Abstracts: A Cross-Disciplinary Study. International Journal of Linguistics, 8(2), 125-140. https://doi.org/10.5296/ijl.v8i2.9379

Ding, H. (2007). Genre analysis of personal statements: Analysis of moves in application essays to medical and dental schools. English for Specific Purposes, 26(3), 368-392. https://doi.org/10.1016/j.esp.2006.09.004 
Dos Santos, M. B. (1996). The textual organization of research paper abstracts in applied linguistics. Text-Interdisciplinary Journal for the Study of Discourse, 16(4), 481-500. https://doi.org/10.1515/text.1.1996.16.4.481

El-Dakhs, D. A. S. (2018). Comparative Genre Analysis of Research Article Abstracts in More and Less Prestigious Journals: Linguistics Journals in Focus. Research in Language, 16(1), 47-63. https://doi.org/10.2478/rela-2018-0002

Farzannia, S., \& Farnia, M. (2017). Genre-based analysis of English and Persian research article abstracts in mining Engineering journals. Beyond Words, 5(1), 1-13.

Feak, C. B., \& Swales, J. M. (2009). Telling a research story: Writing a literature review. University of Michigan Press. https://doi.org/10.3998/mpub.309338

Flowerdew, J. (2014). Academic discourse. Routledge. https://doi.org/10.4324/9781315838069

Ghasempour, B., \& Farnia, M. (2017). Contrastive Move Analysis: Persian and English Research Articles Abstracts in Law Discilline. Journal of Teaching English for Specific and Academic Purposes, 739-753.

Khurshied, H., Mahmood, M. A., Hussain, Z. \& Abdulaziz, M. (2016). Genre Analysis of Urdu Research Article Abstracts. Sci.Int. Lahore, 28(4), 637-642.

Koltay, T. (2010). Abstracts and Abstracting: A Genre and Set of Skills for the Twenty-first Century. Elsevier. https://doi.org/10.1533/9781780630328

Li, Y. (1911). A genre analysis of English and Chinese research article abstracts in linguistics and chemistry. Doctoral dissertation, Sciences.

Lorés Sanz, R., \& Bondi, M. (2014). Introduction [Abstracts in Academic Discourse. Variation and Change. Linguistic Insights, 187, 9-17.

Lorés, R. (2004). On RA abstracts: from rhetorical structure to thematic organisation. English for Specific Purposes, 23(3), 280-302. https://doi.org/10.1016/j.esp.2003.06.001

Majid, T. G., \& Omid, T. (2017). A structural move analysis of the abstract section of ISI articles of Iranian and native scholars in the field of agricultural engineering. International Journal of Research Studies in Language Learning, 7(3), 109-122. https://doi.org/10.5861/ijrsll.2017.1864

Marefat, H., \& Mohammadzadeh, S. (2013). Genre analysis of literature research article abstracts: A cross-linguistic, cross-cultural study. Applied Research on English Language, 2(2), 37-50.

Noorizadeh-Honami, L., \& Chalak, A. (2018). Comparative Analysis of Architecture Research Article Abstracts Written by Native and Non-native Authors: A Cross-linguistic, Cross-cultural Study. Theory and Practice in Language Studies, 8(3), 325-330. https://doi.org/10.17507/tpls.0803.08

Othman, A. K. A. (2011). Genre Analysis: An Investigation of MA Dissertation Abstracts.

Saboori, F., \& Hashemi, M. R. (2013). A Cross-Disciplinary Move Analysis of Research Article Abstracts. International Journal of Language Learning and Applied Linguistics World, 4(4), 483-496

Suntara, W., \& Usaha, S. (2013). Research Article Abstracts in Two Related Disciplines: Rhetorical Variation between Linguistics and Applied Linguistics. English Language Teaching, 6(2), 84-99. https://doi.org/10.5539/elt.v6n2p84

Swales, J. (1990). Genre analysis: English in academic and research settings. Cambridge University Press.

Swales, J. M. (2004). Research genres: Explorations and applications. Cambridge: CUP. https://doi.org/10.1017/CBO9781139524827

Swales, J. M., \& Feak, C. B. (2009). Abstracts and the writing of abstracts (Vol. 2). The University of Michigan Press. https://doi.org/10.3998/mpub.309332

Yakhontova, T. V. (2003). English academic writing for students and researchers. Lviv: PAIS.

Zhang, G., \& Zhang, L. (2014). A Survey of the Research on Research Articles in English for Specific Purposes (1986-2012). Taiwan International ESP Journal, 6(1), 31-51. 


\section{Copyrights}

Copyright for this article is retained by the author, with first publication rights granted to the journal.

This is an open-access article distributed under the terms and conditions of the Creative Commons Attribution license (http://creativecommons.org/licenses/by/4.0/). 